\title{
Viagem a um real desfamiliarizado: performatividade da tecnologia na cena contemporânea
}

\author{
Eli Borges Júnior ${ }^{1}$
}

\section{Resumo}

O presente trabalho pretende refletir sobre alguns dos temas desenvolvidos em pesquisa de mestrado que procura investigar e descrever os impactos das tecnologias digitais sobre as formas de ação na cena contemporânea. Neste texto, fazemos um recorte que busca elucidar como a tecnologia passa a apresentar uma "performatividade" em cena, noção que nos foi inspirada pela Profa. Josette Féral. Com a finalidade de demonstrar como a tecnologia, de forma cada vez mais destacada, passa da coxia ao espaço cênico, apresentamos, a partir de Meyerhold e Piscator, alguns dos aspectos - como os deslocamentos entre ficcional e real - que identificamos como decisivos e precursores de uma nova forma de conceber a presença não humana em cena para, então, reiterá-la em exemplos atuais que aqui brevemente expusemos por meio das metaencenações dos grupos Phila 7, Wooster Group e Ubu.

Palavras-chave: encenações digitais, performatividade tecnológica, teatro e tecnologias digitais.

\begin{abstract}
This paper aims to reflect on some of the themes developed in a master's research that seeks to investigate and to describe the impact of digital technologies on the forms of action in the contemporary scene. In this paper, we make a framework that intends to elucidate how the technology begins to present a "performativity" on the scene, which is an idea inspired by Professor Josette Feral. In order to demonstrate how the technology, in an ever more prominent position, passes from the backstage to the scenic area, we present, from the ideas of Meyerhold and Piscator, some of the aspects - like the displacements between the fictional and the real - that we have identified as crucial and precursory of a new way of conceiving the not human presence on the scene and then to reiterate it in current examples that are briefly exposed here through the "meta-mise-en-scène" of the groups Phila 7, Wooster Group and Ubu.
\end{abstract}

Keywords: digital mise-en-scène, technological performativity, theatre and digital technologies.

\section{Resumen}

Este trabajo establece una reflexión acerca de algunos de los temas desarrollados en la investigación de maestría que trata de analizar y describir el impacto de las tecnologías digitales en las formas de acción en la escena contemporánea. En este texto se hace un corte que busca elucidar cómo la tecnología comienza a presentar una "performatividad" en la escena, idea inspirada por la Profesora Josette Féral. Con el objetivo de demostrar cómo la tecnología, de forma cada vez más prominente, se mueve hasta el espacio de escena, presentamos, a partir de Meyerhold y Piscator, algunos de los elementos - como los desplazamientos entre el ficcional y el real - que hemos identificado como cruciales y precursores de

\footnotetext{
1 Ator e diretor. Integrante do ATOPOS - ECA/USP, centro internacional de pesquisa que estuda o impacto das tecnologias digitais em áreas diversas do conhecimento. Coordena o coletivo AION - Rede de Experimentação Cênica. Graduando em Filosofia pela Faculdade de Filosofia, Letras e Ciências Humanas da USP, desenvolve pesquisa de mestrado na ECA sobre a participação das tecnologias digitais na cena contemporânea. Atualmente, realiza um estágio de pesquisa no Departamento de Teatro da Universidade de Paris VIII (Bolsa BEPE - FAPESP), sob orientação da Profa. Dra. Erica Magris.
} 
una nueva forma de concebir la presencia no humana en la escena para, de este modo, discutirla con ejemplos actuales de "meta-espectáculos" de los grupos Phila 7, Wooster Group y Ubu.

Palabras clave: espectáculos digitales, performatividad tecnológica, teatro y tecnologías digitales.

“Procuro um homem". O ceticismo de Diógenes Laércio, ao repetir essa frase em meio a uma multidão de homens que bem lhe podia encher os olhos, talvez seja um extremo muito radical para pensarmos o conceito de real, questão não só emergente nesta nossa reflexão, mas também pedra de toque existencial do próprio pensar sobre o ser.

Extremo porque nos situa diante de questionamentos-chaves que, se conduzidos a certas veredas filosóficas, inviabilizam nosso próprio discurso linguístico. Basta pensarmos no sofista Protágoras ${ }^{2}$, segundo o qual a realidade é relativa ao próprio homem que a concebe. Ou ainda recorramos ao também radical Górgias ${ }^{3}$, para quem o real, se não inexistente, seria inacessível. Para esse, a linguagem e sua imprecisão acabariam por inviabilizar qualquer reconhecimento ou identificação de uma realidade em pureza absoluta.

Mas, apesar do imbróglio filosófico ao qual nos arriscamos ao empreender uma reflexão que permeie a noção de real, pretendemos aqui trabalhar com um conceito mais operativo, algo que nos permita construir uma articulação com o ficcional, o qual, no limite, compreende algum mecanismo de criação artística, de poiesis, espécie de reatualização sofisticada de um real puro. Sem a intenção de ser impreciso, mas já incorrendo na imprecisão, não nos debruçaremos sobre essa dicotomia, muito menos sobre uma reflexão mais apurada com respeito às suas definições. Pretendemos, nesta breve empreitada pelos espaços vazios em que a reflexão teórica nos imerge, oferecer alguns pontos, não de explicação, mas de problematização da participação das novas tecnologias em encenações contemporâneas e da sua relação com a irrupção de formas de real no confronto constante com a ficção.

Fato é que a tecnologia sempre esteve muito presente desde os primórdios daquilo que alicerçaria os fundamentos do teatro ocidental. Do carro de Téspis, espécie

2 É de Protágoras, contam os filósofos que sobre ele dissertaram, a célebre afirmação de que o homem é a medida de todas as coisas. Ao pensar a realidade como ponto de vista, portanto potencialmente mutável, o sofista descarta qualquer possibilidade de existência de seres ou coisas definidas fora da retórica. A "verdade" não é absoluta como em Platão, mas inconstante, construída e desconstruível pelo próprio discurso.

3 Górgias pensava a realidade de uma maneira muito peculiar e logicamente interessante. Para o sofista, a realidade não existiria pelo simples fato de que duas pessoas não podem pensar, pela linguagem conhecida, em uma mesma coisa ao mesmo tempo. Se algo não pode coexistir em dois lugares, como a mesma coisa, "a realidade", poderia estar simultaneamente em duas mentes diversas? Para Górgias, no mínimo, quando falamos em realidade, podemos até usar o mesmo termo, mas jamais estaríamos nos referindo à mesma coisa. 
de carroça que o primeiro ator grego de que se tem notícia utilizava como transporte e palco para suas apresentações, até nossos dias, época em que a tecnologia, renovada pelo digital, parece atuar como dispositivo potente na instauração de dinâmicas real $\mathrm{X}$ ficcional e assumir novas dimensões na encenação. $E$ nesse movimento, por consequência, ela parece redefinir, ou melhor, dissolver os limites dos cânones que por séculos categorizaram as formas artísticas.

\section{Da coxia ao espaço cênico: o sex-appeal tecnológico}

Parece haver, pois, uma relação de natureza muito interessante entre a participação da tecnologia nas encenações e a transformação da própria noção de representação no teatro. E é desse ponto que partimos. Refletir sobre a questão da performatividade da tecnologia na cena contemporânea não pode prescindir de um percurso, mesmo que breve, sobre o que identificamos como ponto de virada fundamental na história do teatro - e aí nos restringimos às suas manifestações ocidentais e de raiz grega. É a partir daí que a tecnologia parece ocupar, gradualmente, novas posições dentro da encenação, reconfigurando a ação cênica e, junto a outros elementos, concorrendo para um arrefecimento da herança textocêntrica que o teatro de então expressava com vigor.

Quem assume posição privilegiada nesse contexto é a eletricidade, a qual possibilitaria a precipitação de uma infinidade de novos recursos que a representação tradicional, então edificada sobre os pilares do naturalismo e do realismo psicológico, parecia não comportar.

O aperfeiçoamento das tecnologias de iluminação elétrica, na transição do século XIX para o século $X X$, conviveria com uma época em que os símbolos e a poética da sugestão começam a tomar conta tanto da dramaturgia quanto das próprias encenações. A obrigação mimética cede lugar a uma certa emancipação da própria cena. Nesse sentido, Jean-Jacques Roubine nos oferece uma perspectiva bastante reveladora ao relacionar o surgimento da tecnologia da eletricidade ao desenvolvimento de novas formas que marcariam profundamente o teatro concebido à época:

As condições para uma transformação da arte cênica achavam-se reunidas, porque estavam reunidos, por um lado, o instrumento intelectual (a recusa das teorias e fórmulas superadas, bem como propostas concretas que levavam à realização de outra coisa) e a ferramenta técnica que tornava viável uma revolução desse alcance: a descoberta dos recursos da iluminação elétrica (ROUBINE, 1998, p. 20).

O espaço no teatro ganha, portanto, com a ajuda dos recursos de iluminação, novos contornos: cores, sombras e outros efeitos de luz passam a dar vazão ao afã 
pela profundidade das ideias representadas em cena, à busca de uma verdade que as visões realista e naturalista não davam conta de acessar. Era necessário transcender a cena para além dela mesma, invocando ali novas dimensões de reflexão.

Grandes arautos dessa tarefa serão Edward Gordon Craig e Adolf Appia, ao renovarem a cena teatral por meio de sua cenografia abstrata e suas ousadas técnicas de iluminação. Mais do que iluminar propriamente o palco, a revolução da iluminação elétrica no teatro proporcionaria a descoberta de novos espaços de cena, espaços muito mais profundos do que qualquer técnica de perspectiva, por mais sofisticada que fosse, poderia alcançar. A luz elétrica, apesar das muitas encenações que continuavam utilizando-a para iluminar pinturas decorativas e reforçar o jogo de ilusão no teatro, foi uma das grandes responsáveis por trazer à cena o espaço do simbólico, a fluidez das significações abstratas. Em certa medida, ela possibilitaria a denúncia da ineficiência da caixa de cena em jogar com a ilusão, em pretender trazer para o palco o mundo da vida e buscar fazer daquele espaço algo real, disfarçando ao máximo todos os elementos que de alguma forma trouxessem uma dimensão teatral à cena, inclusive a tecnologia.

Nessa via percorre o teatro de Stanislávski, cuja tarefa de conceber a cena como uma impressão fiel do "mundo real" acabava por ocultar ao máximo a dimensão subjetiva do signo, substancialmente vinculado à materialidade do que se apresentava no palco. A busca incessante de fazer da cena uma imitação do real acabava justamente numa própria negação do palco como lugar da ficção, como território de uma teatralidade. Como nos lembra Josette Féral, em Stanislávski está em jogo a verdade da peça; a teatralidade apareceria aí como um desvio, "um excesso de defeitos, um exagero de comportamentos, soando falsa e situando-se distante da verdade cênica" (FÉRAL, 2011, p. 94)4.

Será justamente contra essa concepção que Meyerhold defenderá um teatro que contemple outras esferas de representação, um teatro capaz de sugerir significados ao espectador, sem, no entanto, entregá-los já preenchidos, como faria o teatro naturalista. Era preciso permitir que o espectador adicionasse sua imaginação na fruição do espetáculo, buscando desvendar os "segredos" - termo do próprio Meyerhold - que constituiriam essas lacunas.

O teatro se encontrou de repente nos domínios da indústria. Quis que em cena tudo se desse "como na vida" e se transformou numa espécie de vitrine de objetos de museu. Acreditando em Stanislávski, que o céu do teatro pode se mostrar ao público como o céu de verdade, o trabalho dolorido de

4 Tradução nossa. No original: "Une outrance des effets, une exagération des comportements, sonnant faux et se situant loin de la verité scénique". 
toda a direção teatral passa a ser levantar o urdimento o mais alto possível. Ninguém percebe que em lugar de reformar o palco (que custa tão caro) o melhor é quebrar o princípio que se encontra enterrado nas bases do teatro naturalista. Foi apenas ele, esse princípio, que levou o teatro a essa série de absurdos (MEYERHOLD, 2012, p. 51).

E é sob essa concepção que a tecnologia entrará em cena nas montagens de Meyerhold. Nenhum dos dispositivos cênicos arquiteturais, nem a maquinaria da qual lançava mão, eram de qualquer maneira travestidos sob outras faces: tudo estava sempre visível. E a ilusão definitivamente é rompida quando um telão é alçado na parte superior do fundo da cena, projetando as películas de novos mundos possíveis e impossíveis, fertilizando sonhos e sugerindo espaços indefiníveis de significação que só uma estética simbolista poderia "compreender".

Da maquinaria ocultada pelos recônditos herméticos do urdimento e da coxia passamos ao que começa a se ensaiar como uma performatividade tecnológica, tecnologia essa que, em sua imagem-movimento ou em sua acurada sinfonia de polias e esteiras que passeiam pelo espaço de cena, confunde-se com o próprio movimento cientificamente calculado e precisamente executado dos atores biomecânicos. Parecem anunciar, assim, a sinergia homem-máquina que caracterizaria a sociedade de nossos dias.

Nesse fluxo, há um movimento a priori paradoxal e que nos ajuda a problematizar a questão do real $X$ ficcional: ao mesmo tempo em que a teatralidade é afirmada a todo momento, sem a intenção de fazer da montagem algo real, parece haver uma outra perspectiva que acaba por trazer à cena a própria afirmação do real. Trata-se de um movimento ambíguo e que poderia partir do seguinte raciocínio: o teatral só pode ser afirmado e reconhecido como tal junto à própria afirmação e o reconhecimento, mesmo que indireto, do real. Em outras palavras: seria possível reconhecer o teatral sem considerar o real? Seriam dimensões indissociáveis? Registramos aqui mais um imbróglio filosófico.

Mas, voltando à questão da afirmação do real, vemos que em Meyerhold a tecnologia aparecerá a todo tempo como recurso de registro de uma teatralidade; a tecnologia parece se mostrar ali extremamente imponente e sedutora, catálise de um sex-appeal inorgânico ${ }^{5}$, remetendo-nos mesmo - permita-nos o raciocínio - a uma teatralidade como "modo de atenuação do real tornando-o estético ou erótico" (PAVIS, 2007, p. 324).

5 O filósofo italiano Mario Perniola, herdeiro da tradição estética de Umberto Eco e Alberto Abruzzese, faz uso da expressão "sex-appeal do inorgânico" para se referir, em linhas gerais, a uma forma de sentir contemporânea caracterizada pela mediação sedutora da tecnologia e pelos novos processos comunicativos por ela possibilitados, associados à transformação das relações sociais e estéticas de nossa época (PERNIOLA, 1998). 
Vale ressaltar como esse novo "teatro", que pretende se libertar das antigas formas, nasce já como forma híbrida, intersecção entre formas artísticas diversas: une a secular commedia dell'arte com as técnicas da nova forma do cinema, que ainda não pretende, nem de longe, ser considerada como criação, muito menos arte. As precursoras de nossas encenações digitais, esses primórdios do uso da tecnologia elétrica na projeção de imagens no palco, já nascem filhas de dois mundos, convivendo em simultaneidade com o antigo e o inovador e, mais ainda, utilizando-se dos conflitos por isso gerados como potência inventiva.

Junto às inovadoras técnicas de iluminação, a eletricidade possibilitaria ainda o advento do cinema, que teria no teatro o celeiro inicial de seu grande desenvolvimento. Interessante é também perceber como a participação das tecnologias e, particularmente das técnicas de projeção de imagens no teatro, tangenciam sempre a questão do real $\mathrm{X}$ ficcional, ora tendendo mais a uma afirmação do segundo - como no caso de Meyerhold -, ora como documento do primeiro, caso do teatro de Erwin Piscator.

Piscator reserva um papel singular ao filme em suas encenações, um papel que não se diferenciará apenas nas técnicas aprimoradas de projeção, mas, principalmente, na forma de conceber o próprio filme na cena. Enquanto Meyerhold se apropria do filme como meio de catapultar a abstração sugerida pelo que ocorre no palco - não tendo qualquer compromisso com imagens que exprimissem um documento do mundo real - Piscator assumirá uma postura bastante distinta. Para o encenador alemão, o filme funcionaria como um meio potente de dar expressão à cena, forma de esclarecer superfícies implícitas, narrando ao público conflitos e, a partir desse posicionamento, transformando-a em arena de debate político.

Os telões das projeções, as escadarias rolantes, os elevadores em movimento, enfim, toda a maquinaria que Piscator trazia à encenação estava ali pelo propósito político, tal como os atores e todos os outros elementos constituintes da cena. É impossível deixar de especular que essa maquinaria e seu papel na consecução desses objetivos passam, de certa forma, a rivalizar cada vez mais com o próprio trabalho do ator, na medida em que esse, por mais que trouxesse para a cena os conflitos do mundo real, não daria conta plenamente de trazer toda a realidade objetiva que o filme poderia trazer. No limite, não seria possível negar sua condição de carne e osso e a não vivência direta das circunstâncias retratadas. 


\section{"O real à prova das tecnologias" 6 : a performatividade transorgânica}

Todo esse percurso que fizemos delineando alguns dos principais elementos que marcaram uma rearticulação do papel da tecnologia no teatro - elegendo Meyerhold e Piscator como notáveis exemplos -, juntamente com a reproblematização entre real e ficcional por eles engendrada, fornece-nos pontos de reflexão interessantes no sentido de realizar - mesmo que breve - um passeio por encenações de nossa época nas quais a tecnologia parece exercer uma ação que iria muito além de acessório do ator ou de seu texto.

Não podemos deixar de considerar aí que o surgimento de novas tecnologias parece estar sempre acompanhado pelo advento de importantes transformações nas artes cênicas, alterando suas formas de manifestação ou mesmo o próprio modo de representação dramática. Isso, no entanto, não deve ser compreendido como uma armadura causa-consequencial em tom determinista. O que mais interessa talvez não seja categorizar tal relação, mas demonstrar e analisar como ela tem sido fecunda tanto para as artes cênicas quanto para o próprio desenvolvimento artístico das tecnologias digitais. Fato é que compartilhamos uma época de explosão das tecnologias, em especial as digitais, acompanhada de uma profunda transformação dos próprios modos de se fazer teatro na contemporaneidade. Essa relação seria reconhecida pelo próprio Hans-Thies Lehmann, que, independentemente do que possa ser ressalvado sobre seu conceito de "pós-dramático", identifica linhas de conexão entre as manifestações do teatro contemporâneo e o surgimento das novas "mídias":

\footnotetext{
No curso da ampliação e, em seguida, da onipresença das mídias na vida cotidiana desde os anos 1970, entrou em cena um modo de discurso teatral novo e multiforme, que é designado aqui como teatro pós-dramático (...) No teatro pós-dramático, as linguagens formais desenvolvidas desde as vanguardas históricas se tornam um arsenal de gestos expressivos que lhe servem para dar uma resposta à comunicação social modificada sob as condições da ampla difusão da tecnologia da informação (LEHMANN, 2011, p. 27).
}

A presença e a participação dessas mídias em encenações contemporâneas permitem-nos perceber uma série desses novos traços de uma performatividade da tecnologia que as primeiras décadas do século $X X$ veriam nascer com vigor nos espetáculos de Meyerhold e Piscator. Grupos como La Fura Dels Baus, Ex Machina, Wooster Group, The Builders Association, Collectif Iduun, Station House Opera, Studio Azzurro, Societas Raffaello Sanzio, Ubu, ou mesmo brasileiros como o Phila 7, têm desenvolvido novos formatos de encenação que colocam em xeque até mesmo ques-

6 Expressão utilizada por Josette Féral e Edwige Perrot (2013) em livro com título homônimo e que aqui muito nos é oportuna para refletir sobre a relação real X ficcional na cena tecnológica contemporânea. 
tões primeiras como a percepção de espaço e de tempo de uma forma nunca antes tão arrebatadora. Vejamos alguns exemplos.

- Phila 7 e a transfiguração do espaço-tempo:

Ao organizar o mesmo espetáculo em três países diferentes ${ }^{7}$, a Cia. Phila 7, por exemplo, lida com questões que vão muito além da articulação de um texto ou de uma dramaturgia que dê linearidade e previsibilidade à encenação. A tecnologia ali abre caminho a outras questões, como a problemática da presença orgânica (o ator no palco) e da presença inorgânica (o ator no vídeo), a dissolução das fronteiras físicas de atuação dos atores e a reconfiguração do tempo - na medida em que une três encenações em três fusos horários distintos.

A dramaturgia do espetáculo perde espaço para o que Rubens Velloso, diretor da companhia, caracteriza como uma "tramaturgia porosa", articulação aberta à ciranda infinita dos significados possíveis e que, em certa medida, não deixa de nos remeter aos espaços do "segredo" de Meyerhold. A visualidade do espetáculo, avultada pelo jogo de telas que sincronizam ação no palco com projeção de vídeo, e pelo light design que alia efeitos de iluminação tradicional aos modernos trabalhos com a tecnologia precisa do LED, combina-se a trilha sonora digital, configurando uma cena que descentraliza, por completo, texto e trabalho de ator.

O próprio processo de construção da encenação, particularmente de Play on Earth, deu-se, desde o início, em completa proximidade com a tecnologia. Toda a "tramaturgia" foi desenvolvida a partir de esquetes iniciais encenados em cômodos diversos de um mesmo prédio por meio de transmissão digital. Tal ideia, principiada pelo grupo Station House Opera, seria um dos eixos nos quais se organizaria a encenação final.

O resultado seria um espetáculo em que a tecnologia surge como mediadora fundamental na configuração de novas percepções de espaço e de tempo. Em Play on Earth, nada é sólido, estável, previsível: os espaços explodem as fronteiras geográficas, os tempos cronológicos dos três continentes combinam-se numa cena quase que em suspensão: o real físico do palco dos atores e do espaço da plateia mescla-se às dimensões transfronteiriças dadas pelas tecnologias digitais: surgem reais outros, novas ambiências, lugares moventes por onde as significações navegam sem limites.

\footnotetext{
7 Um dos trabalhos de maior destaque da Cia. Phila 7, de São Paulo, foi montagem de Play on Earth, cuja primeira edição foi encenada em 2006 com a participação simultânea de outros dois grupos internacionais, o Station House Opera, de Newcastle (Inglaterra), e a Cia. TheatreWorks, da capital de Cingapura. A mesma encenação dividia-se em três frentes articuladas ao vivo entre três continentes distintos: América, Europa e Ásia. A segunda edição, em 2008 e com o mesmo formato, foi realizada entre o Rio de Janeiro e Londres.
} 
- Wooster Group e a tecnologia como dramaturgista:

Na reflexão sobre o conceito de teatro performativo, Féral (2011) sinaliza para uma performatividade da tecnologia ${ }^{8}$ como desestabilizadora da teatralidade na medida em que denuncia o jogo da ilusão da cena. Embora não abordemos aqui o grupo The Builders Association, objeto da análise de Féral, poderíamos contemplar o consagrado Wooster Group sob uma perspectiva muito próxima.

Ocorre um fenômeno muito interessante nas encenações do Wooster: em nenhum momento - ou em poucas e breves situações - a tecnologia que permeia os espetáculos está a serviço da tarefa da mimesis. Não há, pois, a obrigação, por parte da tecnologia, de reproduzir efeitos de um real ou de adornar a ficção com o máximo possível de referências de um real. Nas encenações do Wooster - e aqui poderíamos recorrer, como exemplo, a Hamlet $t^{9}$ - tudo o que se faz é reproduzir a gravação de uma montagem realizada na década de 60. Sem adaptação dramatúrgica, sem uma intenção clara de se encenar propriamente o texto shakespeariano, Hamlet nos mostra como o texto pode ser mero pretexto na cena onde a ação predomina: ação não só dos atores, mas e sobretudo, da própria tecnologia.

Será pois, a tecnologia, quem fará toda a articulação do espetáculo: ela parece conectar os atores aos demais elementos da encenação e desenhar, no cinético espaço de cena, marcações arrojadas, construídas pela fisicalidade dos movimentos dos atores e pelos fluxos informativos das telas que descrevem a eles cada segundo do que ali se passa. Ali a tecnologia não só deixa de referenciar o real, como cria novas realidades eletrônicas: colagens, citações, multifacetadas montagens de imagens incessantemente construídas e desconstruídas pelos VJs.

São espetáculos que não funcionam sem a participação da tecnologia. Ali ela é imprescindível. Imprescindível não só tecnicamente, na medida em que possibilita uma infinidade de efeitos sonoro-visuais, mas porque traz claramente uma mensagem implícita - nem sempre - de que tudo aquilo não almeja qualquer referente real. Nem mesmo os atores, cuja precisão e sincronia com o filme nos assusta - tornando-se espetáculo à parte -, vislumbram qualquer construção de personagens: a ação é simplificada em seu puro fazer, um "performativo" em termos schechnerianos.

8 Tal análise de Féral relaciona-se ao grupo The Builders Association, concentrando-se sobre as encenações de Jet Lag e Alladeen. A direção fica por conta de Marianne Weems.

9 Consagrada encenação do Wooster Groop, dirigida por Elizabeth LeCompte, Hamlet busca reproduzir a gravação de uma montagem do texto de Shakespeare realizada em 1964 e que tinha no papel principal a figura de Richard Burton. Os próprios atores denominam o processo como "teatro-filme reverso". 
Não seria exagero pensar o Wooster Group como um dos extremos desse movimento cênico de performatividade tecnológica, movimento que ganharia proporções cada vez maiores a partir da emancipação em relação à mimesis e da libertação para a ausência de fronteiras a que a abstração e os espaços vazios da nova encenação poderiam conduzir.

A tecnologia acabaria, pois, por ampliar a própria cena para além de si mesma. O resultado disso é a criação de uma dimensão estética a nossos olhos bastante estranha, diversa de tudo o que já se viu. Diversa mesmo do que os cânones da arte bradam sobre o próprio teatro. Os filmes de referência que compõem a cena, as fotografias das personalidades narradas pelos atores, os alto-falantes que arriscam a trilha sem ritmo ou harmonia conhecidos pela erudição da música, as máquinas em pleno funcionamento, a labiríntica e conceitual cenografia pespontada pelos cabos e chapas de aço, além do caos harmonizado típico de um jazz em sua época mais efervescente atuam além de uma função acessória na encenação de Hamlet. Tais elementos parecem constituir um movimento que se inicia com a resistência às formas do naturalismo e do realismo psicológico, e que passa a deslocar o espetáculo de uma dimensão textocêntrica para uma encenação em que outros elementos até então, menos considerados, passam a exercer um papel cada vez mais atuante na significação da cena. Por certo, Meyerhold e LeCompte teriam muito a conversar.

- Ubu e o digital como produção de presença:

Assim como a tecnologia pode escancarar as fases da produção de teatralidade, destruindo qualquer formato no qual a ilusão pudesse se abrigar, algumas encenações podem, numa direção diversa, oferecer-nos outras percepções sobre o jogo ilusório gerado pelas imagens em cena. Nesse sentido, destacaríamos o exemplo da encenação de Os cegos, com texto de Maeterlinck e direção de Denis Marleau, fundador do grupo canadense Ubu.

$\mathrm{Na}$ encenação de Marleau, a tecnologia participa de uma outra operação voltada muito mais à produção de presença na cena, do que à manifestação da ausência de atores no palco. Ao assistirmos ao espetáculo - principalmente se ali estivermos desavisados -, nada nos impede de concebermos seus seres falantes como atores fisicamente presentes. Verificamos ali, um potente instrumento produtor de ilusão: o desenho e a confecção precisa das máscaras em $3 \mathrm{D}$, sobre as quais repousa a imagem de rostos com suas particulares marcas e movimentos de expressão, em nenhum momento - 
como, do contrário, ocorre no Hamlet do Wooster Group ou no Play on Earth da Phila 7 - almeja mostrar que aquilo se configura propriamente como um jogo de ilusão.

A ilusão não é denunciada. Pelo contrário, ela parece fluir livre ao longo de todo o espetáculo, chegando mesmo a desnortear o espectador: no final, para quem são os aplausos? Para máquinas falantes? "Fantasmagorias tecnológicas" como o próprio título anuncia? Sobre isso, valem ser lidas as palavras de Stéphanie Jasmin, colaboradora artística de Marleau:

\begin{abstract}
E este efeito de realidade, cujo funcionamento é invisível, contribui talvez para a ambiguidade sentida diante da fantasmagoria tecnológica que Denis Marleau criou com OS CEGOS. Uma ambiguidade que se mostra perceptível na reação dos espectadores, no silêncio total observado durante e depois da sessão aos aplausos hesitantes, incertos e espalhados que às vezes acontecem; esboçados e, em seguida, reabsorvidos diante do absurdo de aplaudir as máquinas e as projeções... O ator e a atriz não mais ali estão. Restam as imagens genéricas de um homem e de uma mulher multiplicadas seis vezes, mas sempre sozinhos com eles mesmos em sua obscuridade eterna (JASMIN, 2002, p. 42) ${ }^{10}$.
\end{abstract}

As máscaras digitais de Marleau passariam despercebidas por vários espectadores: apenas o final do espetáculo revelaria que ali presença orgânica não havia. Como o próprio nome do espetáculo sugeria, "Os cegos - fantasmagoria tecnológica"11, resgata, de certa forma, a ilusão de presença das antigas fantasmagorias, truques de produção de imagens com sombras e luzes que fizeram enorme sucesso na transição do século XVIII para o XIX.

É fato que, na encenação de Marleau, vai-se muito além, na medida em que ali se conjugam aparatos técnicos com um trabalho preciso de ator - o qual embora não seja reatualizado fisicamente no palco a cada apresentação, é, sim, confiado a atuação da tecnologia. Performatividade do ator e performatividade da tecnologia confundem-se, mesclam-se a tal ponto de nos deixar a seguinte mensagem: há mesmo limites entre uma e outra?

10 Tradução nossa. No original: "Et cet effet de réalité, dont les rouages sont invisibles, contribue peut-être au trouble ressenti devant la fantasmagorie technologique que Denis Marleau a créée avec LES AVEUGLES. Un trouble qui s'avère perceptible dans la réaction des spectateurs, du silence total observé pendant et tout de suite après la séance aux applaudissements hésitants, incertains et parsemés qui suivent parfois; esquissés puis résorbés devant l'absurdité d'applaudir des machines et des projections... L'acteur et l'actrice n'y sont plus. II reste les images génériques d'un homme et d'une femme multipliées six fois mais toujours seuls avec eux-mêmes dans leur obscurité éternelle".

11 No original em francês, "Les aveugles, fantasmagorie technologique". 


\section{Metaencenações: a cena para além de si mesma}

Portanto, é com questionamentos ainda mais urgentes que deixamos essa nossa reflexão. Neste breve percurso que fizemos, procuramos mostrar a partir de alguns exemplos e reflexões - que um tempo e um espaço mais extensos poderiam em muito amadurecer -, a relação entre a participação da tecnologia e as transformações que essa acompanharia nas formas cênicas, num processo recíproco e sem qualquer forma de determinismo.

Esta nova dinâmica parece alterar ainda a própria ação cênica, movendo o texto definitivamente do centro da representação. Para além disso, a própria cena tecnológica e, particularmente a digital, envolve-se em um movimento importante e elaborado de expansão de si mesma: passa a se constituir a partir do que se dá fisicamente no palco e na imagem projetada. Esse processo teria a capacidade de engendrar, como destaca Erica Magris (2009), a formação de um verdadeiro "teatro expandido"'12.

Em suma, pretendemos aqui estabelecer alguns pontos de relação entre a saída da tecnologia dos espaços ocultos do palco em direção à própria cena. Essa trajetória nos revelaria uma série de importantes transformações no teatro, alterando por completo as relações ator/expectador, cena/arquitetura cênica e, no limite, a problematização entre real e ficcional. O grande corolário disso tudo seria a forma fugidia, desconfortável e multifacetada pela qual passaríamos a conceber as formas artísticas contemporâneas e, particularmente, aquela que nos cânones ainda se nomeia como "teatro".

\section{Referências}

ANTISERI, D.; REALE, G. História da filosofia. v. 1. São Paulo: Paulus, 1990.

FÉRAL, J. Théorie et pratique du théâtre: au-delà des limites. Montpellier: L'Entretemps, 2011.

PERROT, E. Le réel à l'epreuve des technologies: les arts de la scène et les arts médiatiques. Rennes: Presses Universitaires de Rennes, 2013.

JASMIN, S. Parcours du personnage vidéo, miroir, multiplication et effacement de l'acteur. In: Modernité de Maeterlinck, Denis Marleau - Alternatives Théâtrales 73-74. Belgique, 2002. Disponível em: <www.alternativestheatrales.be/catalogue/revue/73-74>. Acesso em 10 jul. 2013.

MAGRIS, E. Théâtres élargis: les technologies audiovisuelles dans les pratiques théâtrales italiennes (1965-2005). Paris/Pisa: CNRS/SNS, 2009.

12 O conceito de "teatros expandidos" ("théâtres élargis") consiste na tese central do trabalho de doutoramento de Erica Magris, professora do Departamento de Teatro da Universidade de Paris 8 e especialista no estudo das relações entre as tecnologias de comunicação audiovisual e as artes do espetáculo. Na tese, Magris faz uma análise da presença de tais recursos na cena italiana do período de 1965 a 2005 (MAGRIS, 2009), debruçandose sobre as especificidades dessas novas relações principalmente a partir do advento das tecnologias digitais. 
MEYERHOLD, V. Do teatro. Trad. Diego Moschkovich. São Paulo: Iluminuras, 2012.

PAVIS, P. Vers une théorie de la pratique théâtrale. 4. ed. Paris: Presses Universitaires du Septentrión, 2007.

PERNIOLA, M. O sex-appeal do inorgânico. São Paulo: Studio Nobel, 1998.

PLATÃO. Protágoras. Trad. Carlos Alberto Nunes. Belém: Universidade Federal do Pará, 2002.

ROUBINE, J.J. A linguagem da encenação teatral. Trad. Yan Michalski. Rio de janeiro: Jorge Zahar, 1998. 